\title{
Em Busca de um Marxismo Revolucionário e Latino-Americano: uma análise de "Fernando Martínez Heredia: Pensar en tiempo de Revolución" "1
}

Marcos Antonio da Silva ${ }^{2}$

A instigante trajetória de Fernando Martínez Heredia está relacionada, em grande medida, com a Revolução Cubana, e a tentativa de construção de um pensamento social cubano, envolvendo um projeto revolucionário original, com suas potencialidades e limites, seus sonhos e utopias, suas opções, desafios e dilemas e a sua projeção internacional, latinoamericana e terceiro-mundista.

Neste sentido, é possível constatar que esta segue como um dos principais acontecimentos da América Latina no século XX e da intensidade das ações e acontecimentos, da dinâmica das transformações sociais, políticas e econômicas, com seus avanços, retrocessos e encruzilhadas e dilemas contemporâneos, a Revolução Cubana continua inscrevendo a pequena ilha caribenha no imaginário político, intelectual e popular e desafiando as tradicionais análises políticas e sociais sobre sua condição e seu desenvolvimento.

Desta forma, tal qual uma esfinge ou uma entidade afro-caribenha, a história cubana recente ainda precisa ser estudada, (re) conhecida e (re) considerada e o pensamento social de matriz cubana, e revolucionário, permanece como algo a ser descoberto para a devida compreensão da realidade cubana contemporânea.

Isto porque, no caso do pensamento cubano recente, a centralidade da herança eurocêntrica e sua persistência, tanto interna como externamente, associada a presença de um

\footnotetext{
${ }^{1}$ A obra: "Fernando Martínez Heredia: pensar en tiempo de Revolución", organizada por Rafael Magdiel Sánchez (Buenos Aires: CLACSO, 2018), está disponível em: http://biblioteca.clacso.edu.ar/clacso/se/20180524041744/Antologia_Fernando Martinez Heredia.pdf

${ }^{2}$ Doutor em Estudos sobre a Integração da América Latina (PROLAM/USP). Professor do curso de Ciências Sociais e do Programa de Pós-Graduação em Sociologia (PPGS) da Universidade Federal da Grande Dourados (UFGD). Membro do Laboratório de Estudos sobre a América Latina (LIAL). Brasileiro. Email: marcossilva@ufgd.edu.br
} 
marxismo dogmatizado, de corte soviético e fundamentado em manuais e na repetição, marcou a produção cultural e intelectual de e sobre tal processo e moldou, principalmente nos anos 70 e 80 , boa parte do pensamento oficial do e sobre o país, marginalizando a atuação e a divulgação de pensadores que procuraram tratar (e intervir) em tal processo de uma forma original, autenticamente latino-americana, como se constitui o caso emblemático de Che Guevara, cujo pensamento foi revalorizado a partir dos anos 80, inclusive com a importante contribuição de Heredia.

Além disto, a visão oficializada, dogmatizada e superficial, do marxismo afetou o campo das artes e cultura, excluindo o que não estivesse sob controle e o campo das ciências sociais, distanciando-se do impulso libertário original e das tentativas de construção de um pensamento e um caminho próprio para o processo revolucionário cubano, como pode ser observado na famosa 'polémica de los manuales' em meados da década de 60. Desta forma, apesar da presença de José Martí, inúmeros outros pensadores cubanos, do passado ou do presente, foram submetidos a métrica marxista oficial e alguns acabaram marginalizados, inclusive internamente, sendo resgatados ou revalorizados recentemente.

Além disto, é possível assinalar que as recentes transformações (e transições) que ocorrem no país, tanto sob Raúl Castro como Miguel Díaz-Canel, demonstram que o desafio fundamental de construir um socialismo humano e viável, adaptado as novas condições e desafios do século XXI, que mantenha as conquistas sociais revolucionárias em tempos de mercantilização total da vida humana, só poderá ocorrer de maneira profícua com um retorno aos clássicos do pensamento crítico e a recuperação de, parte, dos debates iniciais da Revolução Cubana, e a busca de um caminho próprio, original e latino-americano, para a realização de seus ideais, como podemos observar na obra mencionada..

Neste sentido, este trabalho, ao recuperar e divulgar a produção de Fernando Martínez Heredia, que pode ser considerado um dos maiores intelectuais cubanos revolucionários, se constitui num trabalho fundamental, e muito instigante, para o (re) conhecimento do pensamento crítico cubano e a tentativa de construção de uma revolução original, latinoamericana em toda sua extensão e plenitude e de alternativas atuais para a construção de uma sociedade mais justa e equitativa.

Sendo assim, como aponta o compilador, o jovem filósofo mexicano Rafael Magdiel Sánchez Quiróz, vida e obra se juntaram na busca de uma revolução original pois: "La vida de Fernando Martínez Heredia (FMH, en adelante) se inscribe en el proceso revolucionario que 
vivió por más de 60 años. Años y vivencias que para las ciencias sociales suelen explicarse como excepciones o accidentes, por ser difícilmente asibles a sus métodos de análisis, pero que desde los actores que alteraron la historia se expresa como un esfuerzo -con dimensiones individuales y colectivas más allá de su horizonte nacional, pero bien arraigado a este- por romper con las determinaciones de lo factible. Pasar por encima de lo permisible y hacedero en el ámbito de la reproducción de la vida social. Quebrar las determinaciones de la geopolítica y, en suma, del horizonte histórico de una época y, al hacerlo, echar por la borda las leyes de la ciencia positiva (aun en sus presentaciones críticas), de la determinación de la política, del ser social y su conciencia social por la economía. En suma: romper los límites de lo posible (expresión recurrente de FMH, síntesis de vida y esfuerzos teóricos, y de la herejía cubana que se desató con todas sus fuerzas un primero de enero de 1959) (pag. 16).

A obra é parte integrante da série 'Trayectorias' da coleção de Antologías del Pensamiento Social Latinoamericano y Caribeño, publicada pelo Conselho LatinoAmericano de Ciências Sociais (CLACSO) ${ }^{3}$, composta por cinco séries: Trayectorias, Países, Pensamientos Silenciados, Miradas Lejanas e CLACSO/SIGLO XXI (publicação conjunta), cujos textos podem ser considerados essenciais para conhecer e compreender o pensamento social latino-americano e caribenho, clássico e contemporâneo, e a construção de um caminho próprio, autônomo e original para o desenvolvimento das ciências, e, principalmente, das sociedades latino-americanas, superando o eurocentrismo acadêmico e cultural.

A série Trayectorias, na qual se insere a obra sobre Fernando Martínez Heredia, reúne os textos mais importantes e representativos de destacados intelectuais latino-americanos e possui, até o momento, as seguintes publicações: "Gino Germani: la sociedad en cuestión", “Anibal Quijano: cuestiones y horizontes”, "Miguel Soler Roca: educación, resistência y esperanza", "Roberto Fernández Retamar: Pensamiento anticolonial de Nuestra América”, "Fernando C. Gutiérrez: la construcción social de los derechos y la cuestión social del desarrollo”, "Eduardo Archetti: Antologia Esencial”, “José Aricó: Dilemas del Marxismo en América Latina”, "Franz J. Hinkelammert: La vida o el capital- el grito del sujeto vivo y corporal frente a la ley del mercado", "Norma Giarracca: Estudios rurales y movimientos sociales: miradas desde el Sur", "Elsie Rockwell: Vivir entre Escuelas: relatos y

\footnotetext{
${ }^{3}$ O Conselho Latino-Americano de Ciências Sociais (CLACSO) é uma instituição não-governamental, criada em 1967 e associada a UNESCO, que reúne cerca de 394 centros de pesquisa, programas de pós-graduação ou instituições em ciências humanas e sociais de 26 países da América Latina. Além deste, também são filiadas diversas instituições de EUA, Europa, África e Ásia que se dedicam ao estudo de temas latino-americanos. Para conhecer a entidade pode-se acessar: http://www.clacso.org.ar
} 
presencias", "Gerónimo de Sierra: Cincuenta años de Sociologia Política- Uruguay y América Latina” e “Boaventura de Sousa Santos: Construyendo las epistemologias del Sur”.

A obra sobre Fernando Martínez Heredia apresenta, dentre outros, dois elementos compartilhados pelos autores da coleção. Por um lado, demonstra a unidade entre a obra (as temáticas e as reflexões) e a dinâmica social e política de seu país e região, produzindo um pensamento que procura estar a serviço da transformação social e da construção de sociedades mais justas e solidárias.

Por outro lado, demonstra que estes autores procuram associar compromisso e sensibilidade social com rigor intelectual, desenvolvendo um pensamento que procura compreender, em profundidade, as características de suas sociedades e os processos que as permeiam, desenvolvendo uma crítica profunda da sociedade realmente existente e apontando, na medida do possível, às alternativas necessárias.

Sendo assim, procura compilar e divulgar textos de toda a trajetória revolucionária de Fernando M. Heredia, revelando tanto sua dimensão humana excepcional como sua produção intelectual, marcada pela humildade e originalidade, fornecendo ao leitor uma visão ampla e profunda do autor, assim como o acesso a trabalhos que eram difíceis de serem encontrados.

Neste sentido, podemos assinalar que o trabalho, bem organizado, acompanha a trajetória de Fernando em que se destacam, de forma geral, os seguintes momentos: anos 60Revolução e trabalho no Departamento de Filosofia da Universidade de Havana e na Revista Pensamento Crítico; anos 70- marginalização com atividades burocráticas no Instituto Nacional de Reforma Agrária e no Centro de Estudos sobre a Europa Oriental, até a eclosão da Revolução Sandinista; anos 80 e 90- atuação no CEA, impulsionando (juntos com outros colegas) a recuperação e a difusão da obra de Che Guevara, junto com a assessoria para PCC, voltada a América Latina, e uma colaboração importante com a Casa de las Américas; e, finalmente, a etapa relativa ao século XXI, até sua morte em 2017, de profícua produção e atuação no Centro Juan Marinello, dentre outros.

Para combinar tal trajetória com a produção intelectual, a obra está organizada em dois eixos, que se desdobram em diversas seções.

O primeiro eixo, intitulado 'Sobre la teoria y el pensamiento', reúne trabalhos fundamentais sobre o pensamento do autor e sua relação com o marxismo e o pensamento cubano e latino-americano contemporâneo, demostrando a capacidade deste de produzir uma reflexão profunda e original, manejando o pensamento crítico na melhor tradição dos 
clássicos do marxismo (Marx, Lenin e Gramsci, dentre outros) em que pensar significa (re) descobrir, (re) criar e (re) construir. Este eixo está dividido em três seções.

Na primeira, denominada de Pensamiento Social, destacam-se o trabalho fundamental 'El ejercício de Pensar', que pode ser considerado o manifesto do pensamento de Martínez Heredia, e os textos 'Pensamiento Social y política de la Revolución' que realiza um balanço da trajetória, e dos limites, das ciências sociais em Cuba, apontando para a sua necessária reinvenção.

A seção seguinte, Pensamiento Marxista, reúne trabalhos que discutem a obra de autores marxistas e de Foucault, analisando sua presença em Cuba ou sua contribuição para o desenvolvimento desta corrente, destacando-se os textos 'Marx y el origen del marxismo', 'Gramsci en la Cuba de los años 60' e 'Problemas de la história del pensamiento marxista: los tiempos de Mariátegui', dentre outros. A última seção, 'Pensamiento Político', é dedicada a análise de temáticas que impactaram ou desafiaram a Revolução Cubana relacionados a hegemonia, ao colonialismo, imperialismo e a teologia da libertação em que se destacam os trabalhos 'Revolución Cubana contra los colonialismos y la necesidad de Fanón' e 'Cristianismo y liberación: Revolución en el Cristianismo? Un estudio cubano la Teologia de la Liberación latinoamericana, sus condicionantes y su situación actual'.

O segundo eixo, mais extenso, é intitulado de 'Historia' e reúne trabalhos que versam sobre inúmeras temáticas associadas a dinâmica histórica cubana, em todo o século $\mathrm{XX}$, e do pensamento crítico, bem como entrevistas que apresentam um balanço sobre a vida e obra de Fernando.

Devido a extensão de todo o eixo, é possível assinalar que na primeira seção, "Sobre el estúdio de la historia', se destacam os trabalhos 'Marx, el marxismo, Hobsbawn y nosostros' y 'Visiones actuales de la historia de Cuba', enquanto que nas duas últimas seções, 'Sobre su vida' e 'Entrevistas', emergem textos que apresentam sua trajetória intelectual, que está associada aos avanços e limitações do impulso revolucionário cubano, como 'Un muchacho del interior', 'Todavia no he recurrido la mitad del camino' e 'A cuarenta años del Pensamiento Crítico' e, finalmente, em relação as entrevistas merecem ser destacadas as concedidas a Néstor Kohan e Emir Sader, dentre outras.

Além disto, os demais textos e seções podem ser agrupados da seguinte forma. A terceira seção, 'América Latina', é dedicada a análise da região, reunindo trabalhos escritos a partir dos anos 90, versando sobre a conjuntura da região, os novos projetos e forças políticas 
e os processos de dominação, resistência e construção de alternativas, destacando-se os trabalhos 'Cultura y Política en América Latina', 'Marxismo revolucionário en América Latina actual', 'La Revolución Cubana en el siglo XXI' e 'Siete retos para los jóvenes de América Latina', dentre outros.

Na mesma perspectiva, podemos assinalar a sexta seção, intitulada 'La determinación pessoal' que, ao analisar a trajetória de inúmeros líderes, cubanos e latino-americanos, procura refletir sobre o papel da ação humana na história e seu impacto nos processos revolucionários, influenciando sua dinâmica e direção, em que se destacam, entre outros, os seguintes trabalhos 'Por que Julio Antonio?', 'Guiteras y el socialismo cubano', 'Piñero' e 'Hugo Chávez, identidad y rebeldia latinoamericana'.

Apesar das seções mencionadas reunirem trabalhos importantes do autor, consideramos, no entanto, que as seguintes seções revelam a profundidade e a importância da obra de Fernando Martínez Heredia.

Neste sentido, destacamos a seção dois, 'Sobre la historia de Cuba', e a seção cinco, 'Cuba actual', como momentos em que emergem o intelectual cubano comprometido com o processo revolucionário, mas pensando-o a partir de sua história e tradição, de sua realidade concreta e das demandas e dos desafios próprios, sem o esquematismo dogmático ou a idealização excessiva. Neste sentido, podem ser destacados os trabalhos 'De negros cubanos a cubanos negros', 'Visón de la historia de José Martí: fundamentos y proyectos', 'Introducción a la Revolución cubana del 30', 'Ideas e ideologia en la Segunda República: la posición de Raúl Cepero Bonilla', da segunda seção, e 'Problemas del socialismo cubano', 'Ciencias Sociales cubanas: el reino de todavia?, 'O Cuba o Washington' e 'Sobre el Socialismo y el hombre en Cuba', da seção seguinte.

Da mesma forma, podem ser agrupadas, com destaque especial, por apresentarem as questões fundamentais do pensamento e da atuação de Fernando, as seções quatro, 'Socialismo', e sete, 'Fidel e Che'. Em ambas emergem inúmeras e reflexões sobre a transição socialista, em sintonia com as indicações de Che e Fidel, e, principalmente, a inserção do autor nos embates para a construção de um socialismo efetivo, em que predominasse a construção de uma sociedade justa, consciente e com elaboração própria e original. Neste sentido, destacam-se os textos 'Socialismo', 'Rectificación y profudización del socialismo en Cuba', 'Socialismo Soviético y socialismo cubano. El caso de Antonio Guiteras' e 'Independencia y socialismo en la América Nuestra', da primeira seção, e os trabalhos 'La 
Concepción del Che', 'El pensamiento de Ernesto Che Guevara' e 'Orígenes y vigencia del pensamiento pol'tico de Fidel Castro', conferência de sua última atividade internacional, em 2017.

Desta forma, apesar da centralidade que o compilador aponta a noção de transição socialista como fundamental para a compreensão do pensamento de Fernando, pode-se observar que tal conceito só se torna efetivo na medida em que se relaciona a Cuba, elemento fundamental desta, e a construção do socialismo cubano, e sua dinâmica marcada pela originalidade e repetição, pela convivência tensa entre o modelo soviético, do qual dependia economicamente, e sua história, laços e convergências com os movimentos do terceiro mundo, principalmente da América Latina.

Neste sentido, Cuba foi, sempre, o ponto de partida e o ponto de chegada da reflexão de Fernando Martínez Heredia sobre as diversas temáticas tratadas (socialismo, história, pensamento social, América Latina, ....) e sem a observação desta centralidade, não é possível captar a importância ou a originalidade de seu pensamento ou sua contribuição para a construção de um marxismo latino-americano.

Além disto, é possível perceber que, desta obra, emerge a constatação de que, com acerto, o autor consegue captar a dicotomia entre a unidade e a diversidade que caracterizam a América Latina, ao destacar suas diversas tradições e conjunturas que, no entanto, convergem para uma história e destinos comuns, além de revelar a dinâmica política e social de determinados países e processo que marcaram a região desde a década de 60 .

Neste sentido, demonstra, uma vez mais, que é possível associar compromisso e sensibilidade social com rigor intelectual, desenvolvendo um pensamento próprio, cubano e latino-americano, que combina o global e o regional, o regional e o local e uma análise multidimensional fundamentada na realidade particular da ilha como nos desafios comuns que marcam a região, embora somente em tempos recentes sua importância comece a ser reconhecida, como um dos grandes nomes do pensamento social cubano contemporâneo.

Finalmente, é possível apontar que a obra, assim como toda a coleção de CLACSO, ao apresentar as trajetórias fundamentais do pensamento latino-americano contemporâneo, é fundamental para o conhecimento da América Latina e do Caribe, dos problemas recorrentes e seculares que afetam a região (desigualdade, dominação, submissão, silenciamentos,...) e das possibilidades de construção de alternativas, alicerçadas na construção de direitos 
efetivos, de respeito as culturas e povos originários, de desenvolvimento económico e social, de democracia participativa e inclusiva e justiça social.

No caso de Fernando Martínez Heredia, sua obra mostra-se fundamental para conhecer os caminhos e as encruzilhadas do socialismo cubano, para compreender sua dinâmica e seus desafíos atuais, e, finalmente, que seu destino se entrelaça, de certa forma, com o de Nuestra América, apontando que, apesar do contexto atual adverso, é necessário manter viva a esperança em tempos melhores, pois, segundo ele: "Mi madre nos enseñó a no tenerle miedo a la muerte, que es algo natural. A lo que temo realmente es a que muera nuestro tempo. (...) me sostiene la esperanza de que vendrán los nuevos y crearán un tiempo superior, en el que todos puedan sonreír y hácer bien cosas diferentes [... y] sientan el gozo de la vida como derecho de todos” (pag. 40). À todos, boa leitura! 